\title{
A distância como variável em modelos configuracionais no estudo da distribuição de atividades econômicas urbanas
}

\author{
Distance as a variable of configurational models for understanding the \\ distribution of urban economic activities
}

Leonardo Lima ${ }^{[0, b]}$, Romulo Krafta ${ }^{[0]}$, Búrbara Maria Giaccom Ribeiro ${ }^{[0]}$

[a] Universidade Federal do Rio Grande do Sul (UFRGS), Programa de Pós-graduação em Planejamento Urbano e Regional (PROPUR), Porto Alegre, RS, Brasil

[b] Faculdades Integradas Teresa D’Ávila (FATEA), Lorena, SP, Brasil

\section{Resumo}

Este trabalho demonstra que diferentes modelos configuracionais urbanos podem gerar resultados similares quando se alteram parâmetros de distância imputados nos processamentos. Assim, demonstra-se uma maneira alternativa de se regular modelos configuracionais para a compreensão de fenômenos urbanos: a utilização da distância como variável ajustável. Empiricamente, o fenômeno da distribuição de atividades econômicas urbanas é analisado linearmente comparando as suas localizações com os resultados obtidos pela aplicação de modelos configuracionais sobre redes espaciais urbanas. Para teste da hipótese, as atividades econômicas de três cidades são espacializadas, e, sobre a rede espacial formada por trechos de ruas dessas cidades, são aplicados modelos configuracionais urbanos com variação em seus raios de processamento. Os valores de centralidade resultantes do processamento de cada modelo são correlacionados à distribuição das atividades econômicas nas cidades por meio do coeficiente de correlação de Pearson ( $r$ ). Resultados similares foram obtidos com a aplicação dos mesmos modelos configuracionais urbanos para um conjunto de diferentes cidades, alterando-se apenas a distância considerada no processamento dos modelos. Portanto, mostra-se mais importante ajustar o parâmetro distância do que descobrir qual modelo configuracional consegue descrever como o fenômeno da distribuição de atividades econômicas ocorre. Em outras palavras, dependendo de cada caso, existiriam distâncias que, associadas a determinados modelos, estariam mais ou menos correlacionadas com a maneira como as atividades econômicas se distribuem pela malha urbana. Dessa forma, este trabalho aponta que os modelos configuracionais podem ser ajustados em função de uma distância otimizada, aumentando a correlação com o fenômeno urbano estudado.

Palavras-chave: Centralidade. Distâncias. Redes espaciais urbanas. Atividades econômicas. Coeficiente de correlação de Pearson.

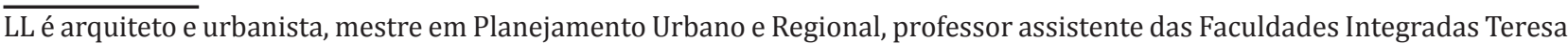
D’Ávila (FATEA), e-mail: leonardo.lima@ufrgs.br

RK é professor titular da Universidade Federal do Rio Grande do Sul (UFRGS), e-mail: krafta@ufrgs.br

BMGR é arquiteta e urbanista, mestre em Sensoriamento Remoto, doutoranda em Planejamento Urbano e Regional, e-mail: barbara.giaccom@ufrgs.br; bgiaccom@gmail.com 


\section{Abstract}

Different configurational urban models can generate similar outcomes by changing the distance parameter used in their processing. The use of distance as adjustable variable is an alternative way of regulating configurational models for understanding urban phenomena. The distribution of urban economic activities is linearly analyzed by comparing their locations with the output of a configurational spatial model for urban networks. To test the proposed hypothesis, the economic activities of three cities were spatialized and urban configurational models were applied on the spatial network of streets segments of these cities, varying the models' processing radius (i.e., the distance parameter). The correlation between values of centrality resulting from each model processing and the distribution of economic activities in the cities were tested with the Pearson's correlation coefficient (r). Similar results were obtained by applying the same configurational urban models for a set of different cities, changing only the distance parameter. We concluded that it seems to be more important to set the distance parameter than to figure out which configurational model can describe how the phenomenon of distribution of economic activity takes place. That is, depending on each case, there would be distances that, associated with certain models, would be more or less correlated with the way economic activities are distributed throughout the urban fabric. Thus, configurational models can be adjusted by an optimized distance, increasing the correlation with the urban phenomenon studied.

Keywords: Centrality. Distance. Urban spatial networks. Economic activities. Pearson's correlation coefficient.

\section{Introdução}

A busca por correlações entre variáveis eminentemente espaciais e fenômenos socioeconômicos é recorrente nos estudos urbanos. Hillier et al. (1993) tentaram descrever o movimento de pedestres associando esse fenômeno a uma propriedade espacial conhecida como "proximidade". Moraes \& Jelvez (2009) relacionaram a sensação de segurança aos lugares com menor distância média para todos os outros dentro da cidade. Porta et al. (2011) afirmaram que a distribuição de atividades econômicas em Barcelona (Espanha) pode ser descrita em função de uma propriedade espacial conhecida como "intermediação". Sevtsuk (2010) sugeriu que uma propriedade espacial, conhecida como "alcance", consegue descrever, com algum rigor, como ocorre a distribuição de atividades econômicas em Somerville, nos Estados Unidos.

Alguns desses estudos consideram a aplicação de modelos configuracionais urbanos variando-se as distâncias dos raios de processamento, no entanto abordam apenas uma cidade por vez. Neste trabalho, compara-se, em diferentes cidades, a aplicação de modelos configuracionais urbanos, considerando-se os mesmos raios de processamento de distância, a fim de demonstrar que modelos diferentes conseguem apresentar resultados de correlação com a distribuição de atividades econômicas que são semelhantes ao se variar apenas a distância durante seus processamentos.

Portanto, o objetivo deste estudo é apresentar uma série de testes empíricos aplicando diversos modelos de centralidade sobre as redes espaciais definidas por trechos de ruas de três cidades brasileiras, variando-se os raios de processamento desses modelos. São utilizados neste estudo os modelos de centralidade por alcance (Watts, 2004), por excentricidade (Vragović et al., 2005), por intermediação (Freeman, 1977) e por proximidade (Hansen, 1959; Ingram, 1971).

Em seguida, utilizando o coeficiente de correlação de Pearson ( $r$ ), procede-se à comparação entre os valores de centralidade obtidos pela aplicação desses modelos e a distribuição de atividades econômicas urbanas. As correlações são agrupadas, e suas variações, analisadas para cada modelo em função dos raios preestabelecidos durante o processamento dos modelos.

É importante frisar que a pesquisa visa explorar apenas as correlações entre variáveis que estariam linearmente associadas. Contudo, fenômenos urbanos são complexos e possuem relações lineares e não lineares. 


\section{Redes espaciais urbanas}

A utilização de modelos configuracionais urbanos requer, previamente, o conhecimento de redes espaciais, uma vez que esses modelos são aplicados sobre elas. Redes espaciais urbanas podem ser entendidas como representações sistêmicas do espaço urbano e têm sido utilizadas para descrever e compreender o espaço de maneira recorrente na geografia quantitativa (Haggett \& Chorley, 1969), de forma tal que se tornaram um instrumento poderoso para a demonstração e validação de hipóteses em experimentos em quaisquer escalas espaciais.

Redes são empregadas, atualmente, nos mais diversos campos do conhecimento. Segundo Strogatz (2001, p. 268) ${ }^{1}$, as redes são utilizadas para estudar

The topology of food webs, electrical power grids, cellular and metabolic networks, the World-Wide Web, the Internet backbone, the neural network of the nematode worm Caenorhabditis elegans, telephone call graphs, coauthorship and citation networks of scientists.

Porém, nesta pesquisa, a noção de redes está associada a uma estrutura espacial formada por um conjunto articulado de espaços urbanos (tais como, ruas e esquinas) e as relações de adjacência existentes entre eles (Wasserman \& Faust, 1994), de tal forma que a cidade pode ser convertida em um grafo urbano. Portanto, aqui, "rede" vincula-se a grafo urbano, cuja noção, segundo Krafta (1994), nada mais é do que:

A synthetic representation of urban space in which elementary portions of space are represented by dots, and the permeability or connectivity between them are represented by lines. In this way, urban graphs represent the elements of public open space, as well as built space, and their basic relationship of adjacency (Krafta, 1994, p. 68) ${ }^{2}$.

\footnotetext{
1 "A topologia de cadeias alimentares, redes de transmissão elétrica, redes celulares e metabólicas, a internet, os servidores de internet, a rede neural do verme nematódeo Caenorhabditis elegans, chamadas telefônicas, coautoria e citações em redes de cientistas" (Strogatz, 2001, p. 268, tradução nossa).

2 "Uma representação sintética do espaço urbano no qual porções elementares são representadas por nós e a permeabilidade ou conectividade entre eles são representadas por linhas. Dessa forma, grafos urbanos representam elementos do espaço público aberto tanto quanto o espaço construído, e suas relações básicas de adjacência" (Krafta, 1994, p. 68, tradução nossa).
}

Existem conceitos associados às redes espaciais urbanas que são fundamentais para a compreensão de aspectos relacionados aos estudos configuracionais. Em primeiro lugar, é necessário admitir que redes espaciais urbanas são formadas por vértices e arestas, em que os vértices (nós) representam unidades espaciais (ou células), e as arestas, as relações entre eles (Blanchard \& Volchenkov, 2009). A segunda noção fundamental é a de que redes espaciais urbanas representam um conjunto de espaços que possui relações de adjacência e justaposição, definidoras das conexões. Assim, se dois espaços possuem relações de adjacência entre si, eles estão conectados. De forma contrária, eles são justapostos e, portanto, não conectados (Krafta, 1994). A última consideração diz respeito ao caminho mínimo (ou caminho mais curto). Essa expressão refere-se ao menor percurso possível que conecta um par de espaços não adjacentes dentro de uma rede espacial, isto é, o caminho mínimo é o menor trajeto, formado apenas por elementos adjacentes dentro de uma rede, conectando dois vértices.

Existem diversas formas de se representar o espaço urbano na forma de uma rede (Kruger, 1979). Essas representações espaciais geram os grafos urbanos sobre os quais são aplicadas as rotinas matemáticas, isto é, os modelos configuracionais urbanos. Nesta pesquisa, por razões operacionais, as cidades dos estudos de caso foram convertidas em redes espaciais definidas por trechos de ruas.

\section{Mapa de trechos de rua}

A representação por trechos de rua é uma representação espacial que se baseia na ideia da conectividade entre espaços (Krafta, 2014). Assim, cada entidade espacial é representada por uma linha definida pelo segmento de rua entre um par de esquinas adjacentes da cidade.

Na Figura 1a, apresenta-se um fragmento urbano e sua respectiva representação espacial por trechos de rua. Na Figura 1b, mostra-se a representação espacial por trechos de rua, em que cada unidade espacial é definida pelo trecho de via entre cada par de esquinas ou intersecção viária. As entidades espaciais estão numeradas. Repare que, matematicamente, um mapa de trechos possui um grafo equivalente, exibido na Figura 1c, e sobre o qual são aplicados os modelos configuracionais urbanos. 


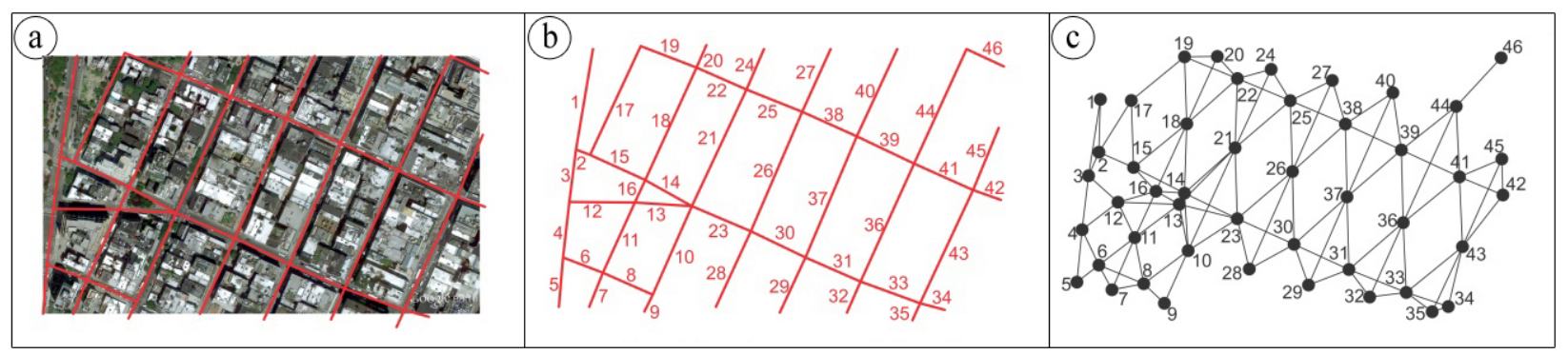

Figura 1 - Representação por trechos de rua Fonte: Lima $(2015$, p. 48).

\section{Modelos configuracionais urbanos}

A necessidade de melhor compreender a realidade urbana faz com que seja necessário, de alguma forma, torná-la experimentável. Para isso, procura-se representar a realidade de forma aceitavelmente simples, mas sem perder de vista aspectos que possam invalidar o caráter científico dos resultados gerados. Com essa finalidade, são utilizados modelos capazes de capturar e manipular aspectos relevantes da realidade de nossas cidades.

Segundo Echenique (1975), modelos não são nada mais do que representações matemáticas simplificadas da realidade. Os modelos configuracionais urbanos admitem que todos os espaços da cidade sejam alcançáveis, e, com a utilização de rotinas matemáticas específicas, torna-se possível diferenciar e hierarquizar elementos do espaço urbano em função de propriedades, como distância (ou proximidade), posição relativa (intermediação), alcance, entre outros. 0 nível de importância que um dado espaço possui nessa hierarquia chama-se centralidade, ou seja, um espaço pode apresentar maior ou menor centralidade do que outro, em função do grau de importância que ele possui dentro da rede formada pelos espaços urbanos, quando se considera uma determinada propriedade espacial. Essa hierarquização de espaços é fundamental para a compreensão das dinâmicas urbanas cotidianas, tanto que Crucitti et al. (2006) afirmam que centralidades são capazes de demonstrar o esqueleto de nossas cidades, enquanto Krafta (2014) argumenta que centralidades permitem descrever a estrutura espacial urbana, isto é, podem desvendar o funcionamento de um sistema de relações desenvolvidas sobre o espaço urbano. Segundo esse autor, a estrutura espacial urbana "não é o espaço em si, mas um tipo de vínculo nele existente" (Krafta, 2014, p. 128).

Assim, os modelos configuracionais urbanos são capazes de hierarquizar os espaços urbanos de acordo com certas propriedades, dentre as quais, são utilizadas neste estudo: alcance (Watts, 2004), excentricidade (Vragović et al., 2005), intermediação (Freeman, 1977) e proximidade (Hansen, 1959; Ingram, 1971).

\section{Modelo de centralidade por alcance}

Como o próprio nome sugere, a propriedade espacial conhecida como alcance está associada à quantidade de espaços diretamente alcançáveis a partir de um determinado espaço na cidade. Essa é uma das características fundamentais do espaço urbano e independe da orientação, ou seja, se dois espaços são adjacentes ("A" e "B"), eles são alcançáveis tanto de "A" para "B" quanto de "B" para "A". Além disso, ela varia conforme se altera a distância, pois, em um primeiro momento, o alcance reflete a quantidade de adjacências que um espaço possui, e, posteriormente, a quantidade de espaços alcançáveis tende a ser incrementada conforme se aumenta a distância considerada.

Portanto, essa propriedade espacial pode ser mensurada de acordo com o grau de alcance que cada espaço possui para todos os outros espaços de um sistema espacial ou somente para os que estão dentro de uma área preestabelecida. Considerando que todos os espaços urbanos são alcançáveis (Nystuen, 1968), ao se levar em conta o alcance de forma global, isto é, computando a distância que os espaços possuem para todos os outros espaços da cidade, tem-se que todos eles terão o mesmo valor de alcance (que é igual ao 
número de vértices da rede menos um). Assim, parece que só faz sentido processar o modelo de centralidade por alcance de forma local, ou seja, considerando um raio predefinido, já que, globalmente (considerando a distância total), todos os espaços apresentarão o mesmo valor.

A operacionalização do modelo de centralidade por alcance é caracterizada por uma operação simples e direta. 0 modelo é capaz de mostrar quantos espaços são alcançados diretamente a partir de um espaço dado, considerando-se um raio preestabelecido. Esse valor tende a aumentar de acordo com o aumento do raio de busca arbitrado no processamento do modelo. Assim, os espaços mais centrais são aqueles que apresentam maior somatório de espaços alcançáveis, a partir de cada um deles, em função de raios predefinidos.

Inicialmente, o modelo avalia a quantidade de espaços diretamente alcançáveis por cada um dos espaços, os quais constituem o sistema espacial urbano. Na sequência, o modelo computa quantos espaços são alcançáveis a partir de um determinado espaço, considerando-se um raio estabelecido inicialmente dado ao seu redor (utilizando a noção de caminho mínimo). Finalmente, a quantidade de outros espaços alcançados por cada espaço do sistema espacial é hierarquizada, de forma que os espaços sejam diferenciados de acordo com seu grau de alcance. Os mais centrais são os que conseguem alcançar o maior número de vértices, considerando-se o mesmo raio de busca para todos os outros espaços da cidade.

Na Figura 2, ilustra-se como o modelo de centralidade por alcance é processado. Admita-se que cada conexão da rede possua comprimento igual a 1 . Nesse caso, o raio de busca definido é igual a 2. Nessa situação, os espaços "B" e "C" são capazes de alcançar a maior quantidade de outros vértices (quatro) conforme a coluna alcance, à direita.

Matematicamente, a centralidade por alcance $C_{A}{ }^{r}[i]$ de um espaço $i$ em um grafo $G$ é igual à quantidade de outros espaços em $G$ alcançáveis a partir de $i$ dentro

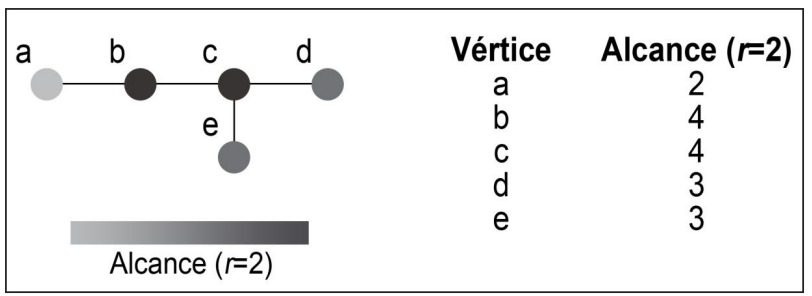

Figura 2 - Modelo de centralidade por alcance Fonte: Elaborado pelos autores (2016). de um raio máximo $r$ definido pelo caminho mínimo (Equação 1) (adaptado de Sevtsuk \& Mekonnen, 2012, p. 10).

$C_{A}{ }^{r}[i]=\|\{j \in G-\{i\}: d[i, j] \leq r\}\|$

Em que: $d[i, j]$ é o caminho mínimo entre os nós $i$ e $j$ no grafo $G$, e $\|S\|$ é a quantidade de elementos do conjunto $S$.

\section{Modelo de centralidade por excentricidade}

Para se compreender o funcionamento do modelo de centralidade por excentricidade, é necessário conhecer uma propriedade espacial conhecida como eficiência. A cidade é formada por um conjunto de barreiras e de permeabilidades que definem a distância entre um par de espaços. Existem deslocamentos urbanos que podem ser realizados de forma direta, ou seja, sem a necessidade de contornar nenhuma barreira. Porém, existem outros que necessitam de várias mudanças de direção, seja por restrições impostas por leis de trânsito ou porque existem obstáculos intransponíveis, como um muro, um acidente geográfico, um rio etc. E essas mudanças de direção significam maiores deslocamentos. Assim, chega-se à conclusão de que quanto maior a quantidade de mudanças de direção, menor será a eficiência dos mais diversos fluxos urbanos.

Autores sugerem que a eficiência de um determinado espaço é dada pela menor variação de distância na conexão dele com todos os outros espaços que compõem um sistema espacial (Vragović et al., 2005). Assim, se a comunicação de um dado espaço com seus pares for, em média, menos excêntrica, tem-se um espaço considerado eficiente. No entanto, se a comunicação dele com seus pares é demasiadamente excêntrica, se tem um espaço pouco eficiente. Assim, a compreensão do termo "eficiência" aqui está associada a duas maneiras de se medir a distância entre um par de espaços. A primeira delas é chamada de distância virtual, isto é, a distância entre um par de espaços é dada pela reta que os conecta diretamente sem considerar quaisquer barreiras impostas pela configuração do espaço urbano. A segunda é chamada de distância real, isto é, para se alcançar um determinado espaço na cidade, é necessário contornar barreiras impostas pela configuração do espaço (considerando-se a noção 
de caminho mínimo). Assim, se a relação distância virtual pela distância real for próxima de 1 , se tem um deslocamento pouco excêntrico (eficiente). Porém, se essa relação tender a 0 , se tem um deslocamento muito excêntrico, ou seja, pouco eficiente.

A operacionalização do modelo de centralidade por excentricidade se dá, inicialmente, pelo cômputo das distâncias virtual e real que cada espaço possui para todos os outros espaços que com ele compõem um sistema espacial (para a distância real, é levado em consideração a noção de caminho mínimo). Depois, o modelo calcula os níveis de excentricidade de cada deslocamento entre os pares de espaços da cidade e os hierarquiza em função de suas excentricidades médias. Aqueles espaços que apresentam os menores valores de excentricidade média, ou seja, os mais eficientes, são os mais centrais. No entanto, os espaços com maiores valores de excentricidade, ou seja, os menos eficientes, são os menos centrais.

Na Figura 3, ilustra-se o processamento do modelo de centralidade por excentricidade. Admita-se que cada conexão da rede possua comprimento igual a 1 . As linhas pontilhadas indicam as distâncias virtuais entre os pares de espaços (não são demonstradas aquelas linhas que apresentam relação entre a distância real e a distância virtual igual a 1, como os pares A-B, A-C etc.). $\mathrm{O}$ espaço "C" apresenta somatório de relações entre a distância virtual (linha reta ou euclidiana) e a distância real (imposta pelas restrições da rede) nos deslocamentos possíveis na rede igual a $4(1+1+1+1)$. Já o espaço "E" possui valor de excentricidade igual a $3,14(0,74+0,70+1+0,70)$. Portanto o espaço "E" é mais excêntrico do que o espaço "A".

A definição matemática da centralidade por excentricidade é dada pela Equação 2 (adaptado de Sevtsuk \& Mekonnen, 2012, p. 14).

$$
C_{E}[i]^{r}=\sum_{j \in G-\{i\}, d[i, j] \leq r} \frac{\delta[i, j]}{d[i, j]}
$$

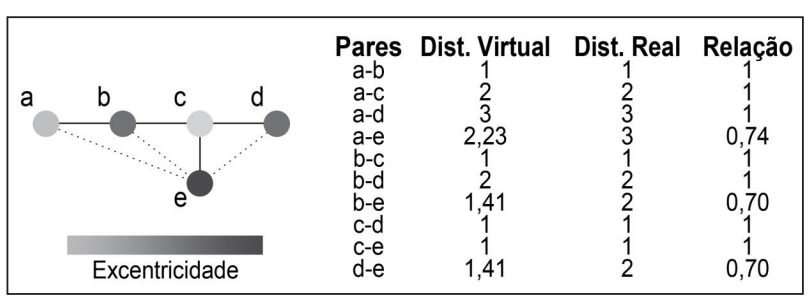

Figura 3 - Modelo de centralidade por excentricidade Fonte: Elaborado pelos autores (2016).
Em que: $C_{E}[i]^{r}$ é a centralidade por excentricidade do espaço $i$ dentro de um raio de busca $r, \delta[i, j]$ é a distância em linha reta (euclidiana) entre os espaços $i$ e $j$, e $d[i, j]$ é o caminho mínimo (distância real) entre esses espaços, considerando as restrições impostas pela rede.

\section{Modelo de centralidade por intermediação}

A intermediação é uma propriedade espacial verificada naqueles espaços que se localizam no trajeto mais curto conectando um par de espaços quaisquer, ou seja, é uma propriedade da qual é possível gerar hierarquia de espaços urbanos em função de seu caráter corredor.

Essencialmente, esse modelo diz que a importância de um espaço é definida pela fração de caminhos mais curtos entre pares de outros espaços que passam por ele (Krafta, 1994). Inicialmente, esse modelo calcula os caminhos mais curtos entre cada par de espaços que não é diretamente conectado ${ }^{3}$. Depois, computa-se a quantidade de vezes que cada espaço aparece intermediando relações entre outros pares quaisquer. Finalmente, é feita a hierarquização dos espaços em função da quantidade de vezes que eles aparecem nos caminhos mínimos de todos os deslocamentos possíveis realizados na cidade. A centralidade por intermediação pode ser calculada de forma local (considerando somente aqueles espaços localizados dentro de um raio estipulado) ou global (considerando todos os espaços da cidade). Se mais de um caminho mínimo é encontrado entre um par de nós (como acontece frequentemente em redes espaciais urbanas), então a cada um dos caminhos equidistantes é dado o mesmo peso, de tal forma que a soma das parcelas seja igual ao valor total (Sevtsuk \& Mekonnen, 2012). 0 modelo de centralidade por intermediação é matematicamente definido pela Equação 3 (adaptado de Sevtsuk \& Mekonnen, 2012, p. 12).

$$
C_{I}[i]^{r}=\sum_{j, k \in G-\{i\}^{\prime}, d[j, k] \leq r} \frac{n_{j k}[i]}{n_{j k}}
$$

Em que: $C_{I}[i]^{r}$ é a centralidade por intermediação de um espaço $i$ em um dado raio de busca $r, n_{j k}[i]$ é a quantidade de caminhos mínimos do nó $j$ até o nó $k$

\footnotetext{
$\overline{{ }^{3} \text { Se dois nós na rede estão diretamente conectados, então não }}$ existe centralidade entre eles.
} 
que são intermediados pelo nó $i$ e $n_{j k}$ é a quantidade total de caminhos mínimos do nó $j$ até o nó $k$ (inclusive os que passam por $i$ ). A intermediação de um espaço $i$ é computada considerando todos os pares de espaços $j, k$ que estão dentro de um raio de distância $r$ um do outro.

Na Figura 4, exemplifica-se o processamento do modelo de centralidade por intermediação. Admita-se que cada conexão da rede possua comprimento igual a 1. É possível perceber que o espaço "C" está intermediando cinco percursos, entre todos os possíveis deslocamentos realizados na rede. 0 espaço "B" aparece em três deles. Os demais, que são extremidades, não intermedeiam nenhuma relação. Portanto o espaço "C" é o mais central.

\section{Modelo de centralidade por proximidade}

Proximidade, ou acessibilidade, é uma propriedade configuracional originada das relações de distância entre diferentes espaços. Distância, nesse sentido, pode não estar somente associada a ideias de unidades geométricas (metros, quilômetros, milhas etc.), mas também a tempo de deslocamento, custos, topologia, entre outras.

Um espaço é considerado mais acessível do que outro se sua distância média, para todos os outros espaços que com ele compõem um sistema espacial, for menor. Pesquisas indicam que, se um espaço está em média mais próximo de todos outros, ele deve apresentar, fatalmente, maiores concentrações de pedestres (e.g., Hillier et al., 1993) e maiores valores de renda da terra (e.g., Barra, 1979).

A literatura aponta que os primeiros a operacionalizar essa propriedade foram Hansen (1959) e Ingram (1971). Para este último autor (Ingram, 1971), a acessibilidade é uma propriedade do espaço que pode ser entendida de duas maneiras: de forma relativa e

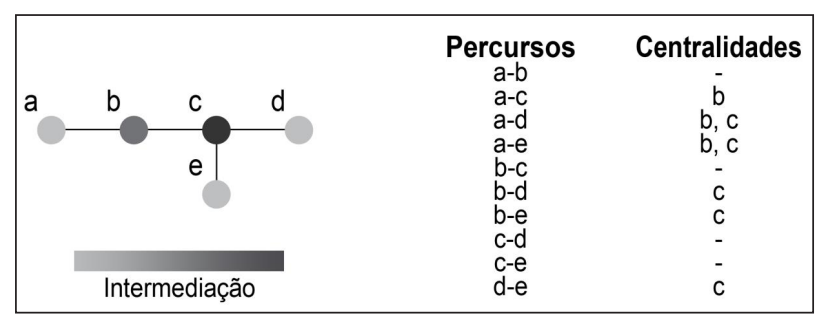

Figura 4 - Modelo de centralidade por intermediação Fonte: Elaborado pelos autores (2016). de forma global. A acessibilidade relativa está ligada à noção de distância existente entre um dado par de espaços e pode ser entendida como o quão distantes eles estão um do outro. Já a acessibilidade global diz respeito à relação de distância entre um espaço e todos os outros existentes em um dado sistema espacial (Ingram, 1971). Assim, a acessibilidade pode gerar uma hierarquia capaz de demonstrar os espaços mais e menos próximos de todos os outros dentro de uma cidade.

0 modelo de centralidade por proximidade é executado, inicialmente, calculando todos os caminhos mínimos entre cada par de espaços do sistema espacial. Depois, é extraída uma média da distância que cada espaço possui para os demais. Por fim, hierarquizam-se os espaços em função de seus valores de distância mínima média, de forma que os espaços com os valores médios mais baixos são os mais acessíveis, e os espaços com os valores médios mais elevados, os menos acessíveis. Formalmente, esse modelo é definido como o somatório do inverso da distância que cada elemento do sistema espacial possui para todos os demais.

A proximidade pode ser calculada de forma local, ou seja, admitindo-se a existência de um raio dentro do qual serão computadas as distâncias mínimas de cada espaço, ou de forma global, no qual todos os elementos, independente de um raio preestabelecido, são considerados.

Portanto, a proximidade indica o quão distante um dado espaço está de todos os outros ao redor de um determinado limite de distância, sugerindo o grau de facilidade com que esse espaço é encontrado na cidade. A representação matemática do modelo de centralidade por proximidade é dada pela Equação 4 (adaptado de Sevtsuk \& Mekonnen, 2012, p. 13).

$C_{P}[i]^{r}=\sum_{i=0}^{n} 1 / d_{i j}$

Em que: $C_{P}[i]^{r}$ é a centralidade por proximidade de um espaço $i$ em um dado raio de busca $r$ e $d$ é a distância mínima entre os espaços $i$ e $j$.

Na Figura 5, é ilustrado o processamento do modelo de centralidade por proximidade. Admita-se que cada conexão da rede possua comprimento igual a 1. À direita, exibe-se a extensão dos caminhos mínimos entre cada par de vértices possível na rede e o inverso do somatório dessas distâncias. Assim, tem-se que o espaço "C" possui a menor distância para todos os 


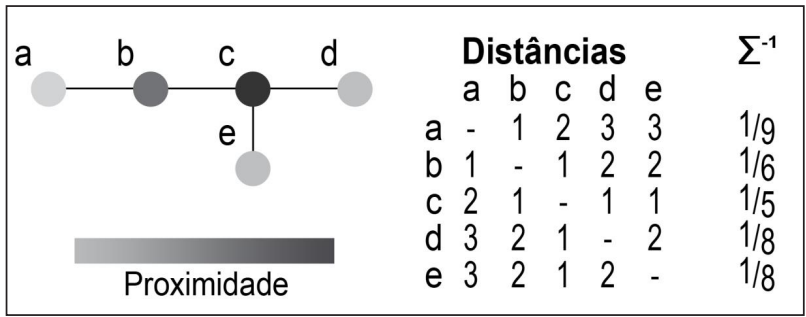

Figura 5 - Modelo de centralidade por proximidade

Fonte: Elaborado pelos autores (2016).

outros vértices da rede (inverso do somatório igual a 0,20 ). Já o espaço "A" é o que está mais distante de todos os outros espaços, ao apresentar o valor inverso do somatório igual a 0,11.

Arbitrariamente, definiu-se que os modelos aplicados nesta pesquisa seriam processados considerando-se raios que obedecessem a uma progressão aritmética de razão igual a $300 \mathrm{~m}$, com o valor inicial adotado de $200 \mathrm{~m}$. Portanto, os experimentos foram realizados com 200, 500, 800, 1.100 m, e assim por diante, até que o limite da rede espacial urbana fosse alcançado.

\section{As atividades econômicas}

Neste trabalho, entende-se por atividades econômicas uma série de estabelecimentos que presta quaisquer tipos de comércios e serviços. Assim, todos aqueles estabelecimentos que geravam qualquer tipo de troca comercial na cidade foram considerados, sejam eles formais ou informais, com a inclusão neste estudo desde pequenos profissionais autônomos até grandes corporações industriais.

\section{Carregamento das redes espaciais}

urbanas com as atividades econômicas

Após realizar a conversão do sistema espacial da cidade em uma representação de trechos de ruas, foi necessário atribuir a cada uma das entidades espaciais (trechos de rua) uma determinada quantidade de atividades econômicas que foram espacializadas em cada um dos estudos de caso.

O levantamento das atividades econômicas que ocorreram nas cidades analisadas nos estudos de caso, deu-se pela observação, in loco, dos mais diversos estabelecimentos que prestavam quaisquer tipos de serviços e comércios nas zonas urbanas dos munícipios estudados e pela utilização do programa Google Earth-Pro (modo Street View). Essa etapa implicou uma pesquisa de campo intensa, realizada sobre as ruas localizadas nas áreas urbanas dos municípios analisados. A cada atividade econômica atribuiu-se um ponto (em formato vetorial). Posteriormente, o conjunto de dados foi espacializado em ambiente SIG (Sistema de Informação Geográfica).

A atribuição da quantidade de atividades econômicas sobre cada entidade espacial (trecho de rua) foi realizada levando em consideração apenas a menor distância entre o par atividade econômica/trecho de rua. Esse procedimento foi realizado por meio de técnicas de geoprocessamento que calculam a distância de cada feição vetorial das localizações de atividades econômicas (pontos) para as unidades espaciais (trechos). Na Figura 6, demonstra-se a maneira como os carregamentos de atividades econômicas foram atribuídos aos trechos de rua.

A Figura 6a apresenta um fragmento urbano, sua representação por trechos de rua (linhas vermelhas) e as atividades econômicas (pontos azuis) nela alocadas. Na Figura 6b, verifica-se a distribuição das atividades econômicas e sua proximidade com os trechos de rua que estão numerados. Na Figura $6 c$, o gradiente de tons vermelhos representa as quantidades de atividades econômicas atribuídas a cada trecho de rua.

A fim de se aumentar a diferenciação entre as quantidades de atividades econômicas alocadas em cada trecho de rua, nós normalizamos a quantidade de atividades econômicas nas entidades espaciais por suas respectivas extensões. Isso se fez necessário, pois, quando se normaliza a quantidade de atividades econômicas pela extensão da entidade espacial, se obtém - para cada entidade espacial - um valor muito particular, haja vista que, muitíssimo raramente, haverá entidades espaciais com a mesma extensão e a mesma quantidade de atividades econômicas alocadas, simultaneamente. Quando não se realiza essa normalização, muitas entidades espaciais apresentam quantidades idênticas de atividades econômicas. Sendo essas quantidades iguais, os valores de correlação de Pearson ( $r$ ) oriundos da comparação da quantidade de atividades econômicas com os valores de centralidade por entidade espacial podem ser minimizados, já que medidas de diferenciação espacial hierarquizam cada unidade do espaço de forma muito peculiar.

Finalmente, é importante salientar que as localizações das atividades econômicas não foram ponderadas por quaisquer índices (como área, 


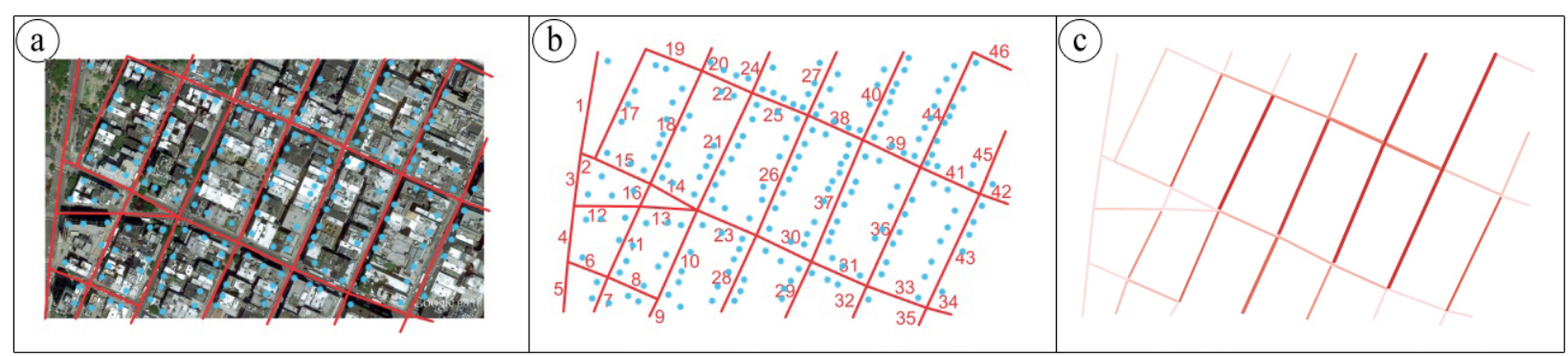

Figura 6 - Carregamento de uma representação espacial por trechos de rua com atividades econômicas Fonte: Lima $(2015$, p. 51$)$.

número de funcionários, faturamento, entre outros). Só interessou aqui estabelecer uma correlação entre a quantidade bruta de estabelecimentos por extensão de entidade espacial e seus respectivos valores de centralidade.

\section{Coeficiente de correlação de Pearson (r)}

A comparação entre as centralidades oriundas da aplicação dos modelos configuracionais urbanos e a distribuição de atividades econômicas se dá pela aplicação de um índice capaz de associar o grau de correlação linear entre essas duas variáveis. Esse índice é obtido pela aplicação do coeficiente de correlação de Pearson $(r)$. Esse coeficiente é capaz de avaliar o grau em que dois fenômenos quantificáveis distintos estão associados linearmente. Matematicamente, a fórmula do coeficiente de correlação de Pearson $(r)$ é dada pela Equação 5.

$$
r=\frac{n \cdot \sum(x \cdot y)-\sum(x) \cdot \sum(y)}{\sqrt{n \cdot \sum x^{2}-\left(\sum x\right)^{2}} \cdot \sqrt{n \cdot \sum y^{2}-\left(\sum y\right)^{2}}}
$$

Em que: $r$ é o coeficiente de correlação de Pearson entre duas variáveis ("A" e "B"), $n$ é o número de elementos avaliados na amostra, $x$ representa os valores individuais da variável " $\mathrm{A}$ " e $y$ representa os valores individuais da variável " $\mathrm{B}$ ".

\footnotetext{
${ }^{4}$ Nesta pesquisa, os valores das variáveis "A" e "B" foram, respectivamente: (A) a quantidade de atividades econômicas normalizadas pela extensão de cada entidade espacial - trecho de rua - e (B) os resultados da aplicação de cada um dos modelos de centralidade apresentados, processados sobre a representação espacial definida por trechos de rua das cidades dos estudos de caso.
}

0 resultado consiste em uma escala adimensional que varia de $-1 \mathrm{a}+1$ (Pearson, 1900). Se dois fenômenos são lineares, porém inversamente correlacionados, tem-se $r$ igual ou próximo de -1. No entanto, se dois fenômenos são lineares e diretamente correlacionados, tem-se $r$ igual ou próximo de +1 . Quanto mais próximo de 0 , menor a linearidade entre os fenômenos e, portanto, menos correlacionados eles são.

É importante ressaltar que, a fim de otimizar os valores dos resultados, aquelas entidades espaciais que não apresentaram atividades econômicas associadas foram suprimidas do cálculo do coeficiente de correlação de Pearson ( $r$ ) com centralidades urbanas. Portanto, os resultados de correlação obtidos nesta pesquisa só levaram em consideração aquelas entidades espaciais que possuíam valores de atividades econômicas diferentes de 0 , normalizadas pela respectiva extensão de cada entidade espacial considerada.

\section{Metodologia}

Inicialmente, as cidades dos estudos de caso foram convertidas em redes espaciais urbanas definidas por trechos de rua. Simultaneamente, as atividades econômicas foram espacializadas em visitas realizadas in loco nas cidades analisadas. Com as representações espaciais concluídas, realizaram-se os carregamentos com as atividades econômicas espacializadas nas cidades, em função de sua proximidade para cada entidade espacial das representações. Então, a quantidade de atividades econômicas por trechos de rua foi normalizada pela extensão dos respectivos trechos de rua. Procedeu-se ao processamento dos modelos configuracionais urbanos apresentados, alterando-se a variável distância, conforme o caso. Na sequência, excluíram-se aquelas entidades espaciais 
que não estavam vinculadas a nenhuma atividade econômica e, finalmente, aplicou-se o coeficiente de correlação de Pearson ( $r$ ), a fim de se avaliar o grau de linearidade entre os resultados obtidos após a aplicação dos modelos configuracionais urbanos e a quantidade de atividades econômicas por entidade espacial.

Por meio da Figura 7, demonstra-se o procedimento correlacional. À esquerda, uma representação espacial definida por trechos de rua é processada com um modelo configuracional urbano de forma global. Cada entidade espacial está identificada por uma letra. 0 gradiente de tons vermelhos indica os trechos mais e menos centrais, conforme o modelo configuracional empregado. Os círculos azuis representam localizações de atividades econômicas. À direita, a matriz informa: (1) a extensão de cada trecho; (2) a quantidade de atividades econômicas associadas, por proximidade, a cada um dos trechos; (3) a relação entre a quantidade de atividades econômicas por extensão da entidade espacial; finalmente, (4) os valores de centralidade de cada entidade espacial. Na parte inferior, são apresentados o valor de correlação de Pearson $(r)$ (5) entre as centralidades, a quantidade bruta de atividades econômicas por trecho de rua $\left(r_{1}=0,47\right)$ e (6) as centralidades e a quantidade de atividades econômicas normalizadas pela extensão dos trechos de rua $\left(r_{2}=0,93\right)$.

0 presente estudo apresentou experimentos de forma análoga à maneira como o segundo valor de correlação de Pearson $(r)$ foi obtido. Note-se que, visando maximizar o valor correlacional, a entidade com valor nulo de atividades econômicas (a) foi excluída do cálculo correlacional.

\section{Estudos de caso}

Os experimentos foram realizados utilizando-se três cidades de pequeno e médio porte das regiões Sudeste e Sul do Brasil. Essas cidades foram escolhidas em função do maior grau de disponibilidade e facilidade de acesso a dados e de possibilidade de levantamento de dados in situ.

A primeira cidade, aqui denominada "Cidade L", localiza-se na região Sudeste do país, no Estado de São Paulo, e possui uma população de cerca de 86 mil habitantes (IBGE, 2013). O levantamento das atividades econômicas na Cidade L resultou em 2.736 pontos, e sua representação espacial por trechos de rua possuiu 2.618 entidades espaciais. No mapa da Figura 8, demonstram-se a representação espacial e a distribuição de atividades econômicas na Cidade L.

A segunda cidade, chamada de "Cidade P", também está localizada na região Sudeste do Brasil, mais especificamente no litoral do Estado do Rio de Janeiro, com população em torno de 40 mil habitantes (IBGE, 2013). Conforme ilustrado na Figura 9, foram espacializadas 1.350 localizações com atividades econômicas na Cidade P, cuja representação espacial definida por trechos de rua possuiu 709 entidades.

0 terceiro estudo de caso é a Cidade T, que está localizada na região Sul do Brasil, no Estado do Rio Grande do Sul. É uma cidade litorânea com cerca de 37 mil habitantes (IBGE, 2013). Nessa cidade, foram espacializadas 1.445 atividades econômicas, e sua representação espacial por trechos de rua possuiu 1.178 entidades, conforme apresentado por meio do mapa da Figura 10.

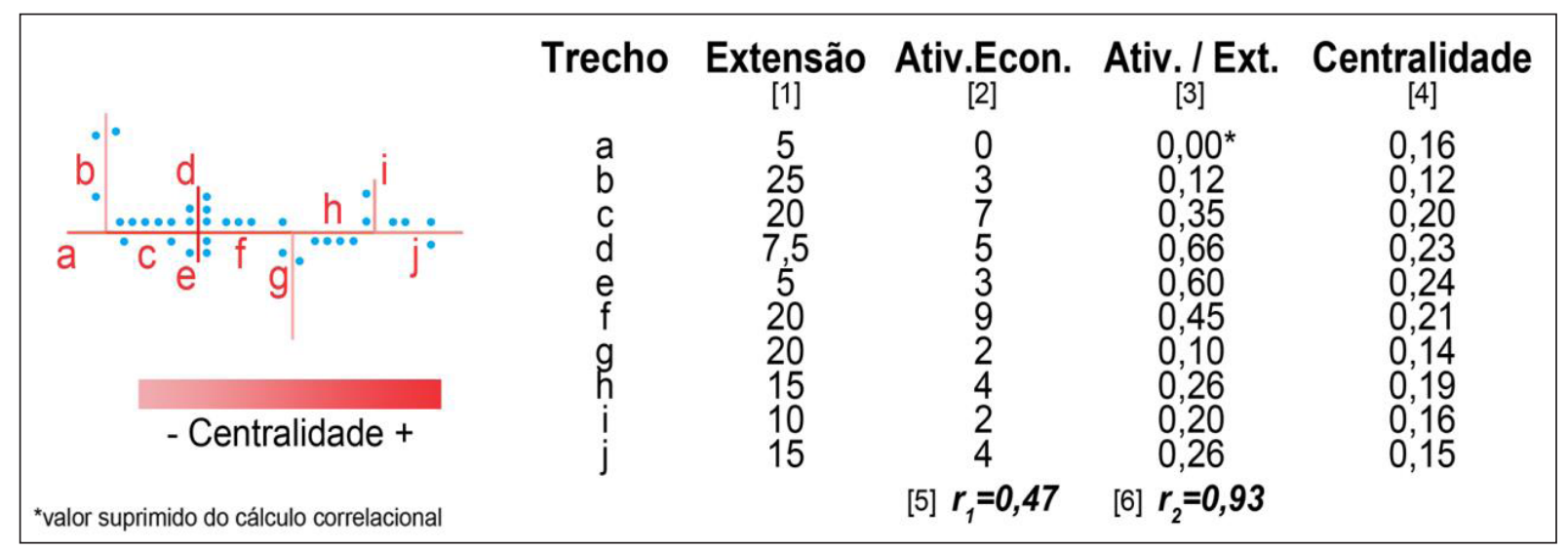

Figura 7 - Experimento-piloto

Fonte: Elaborado pelos autores (2016). 


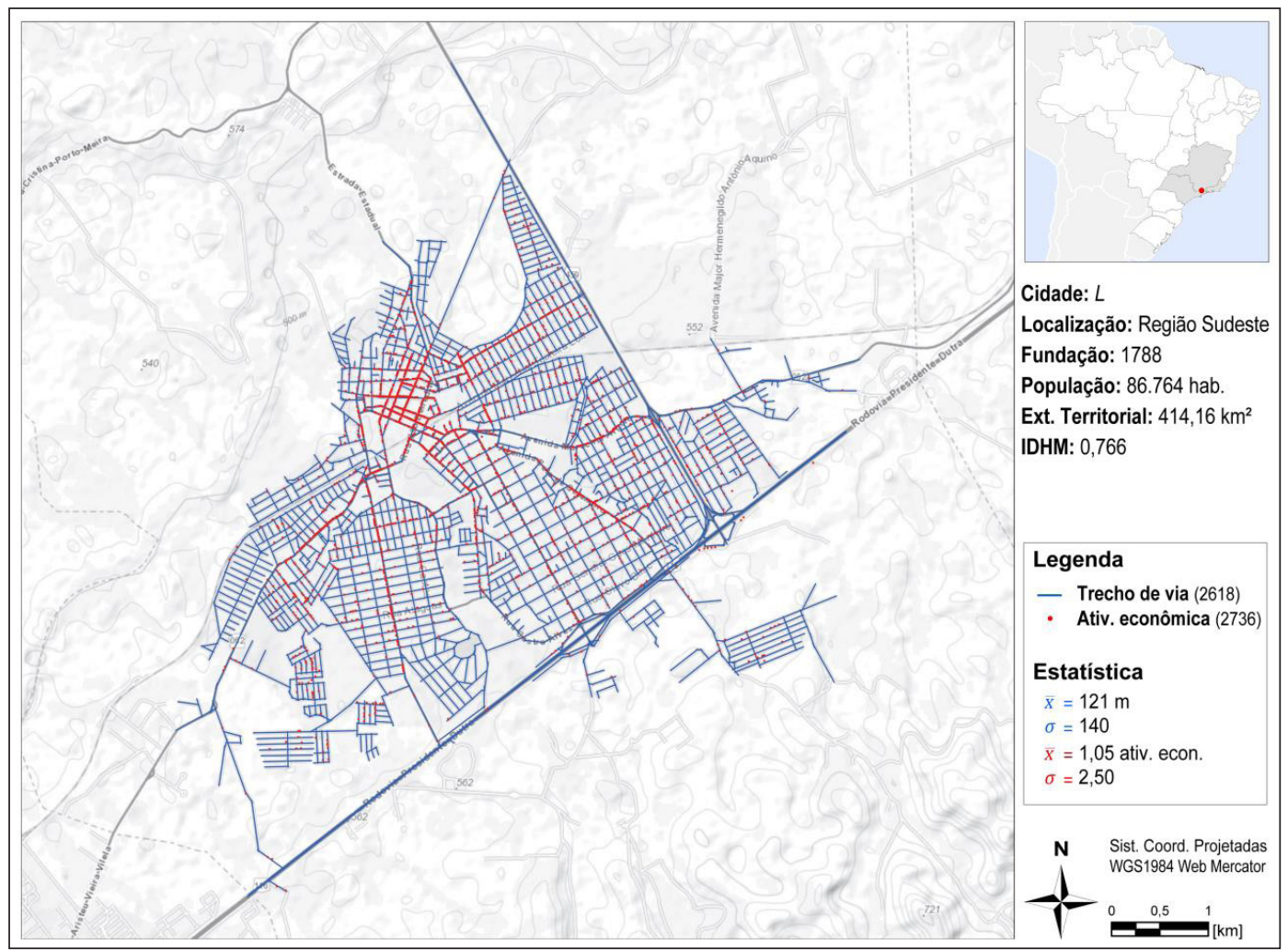

Figura 8 - Cidade L

Fonte: adaptado de Lima (2015).

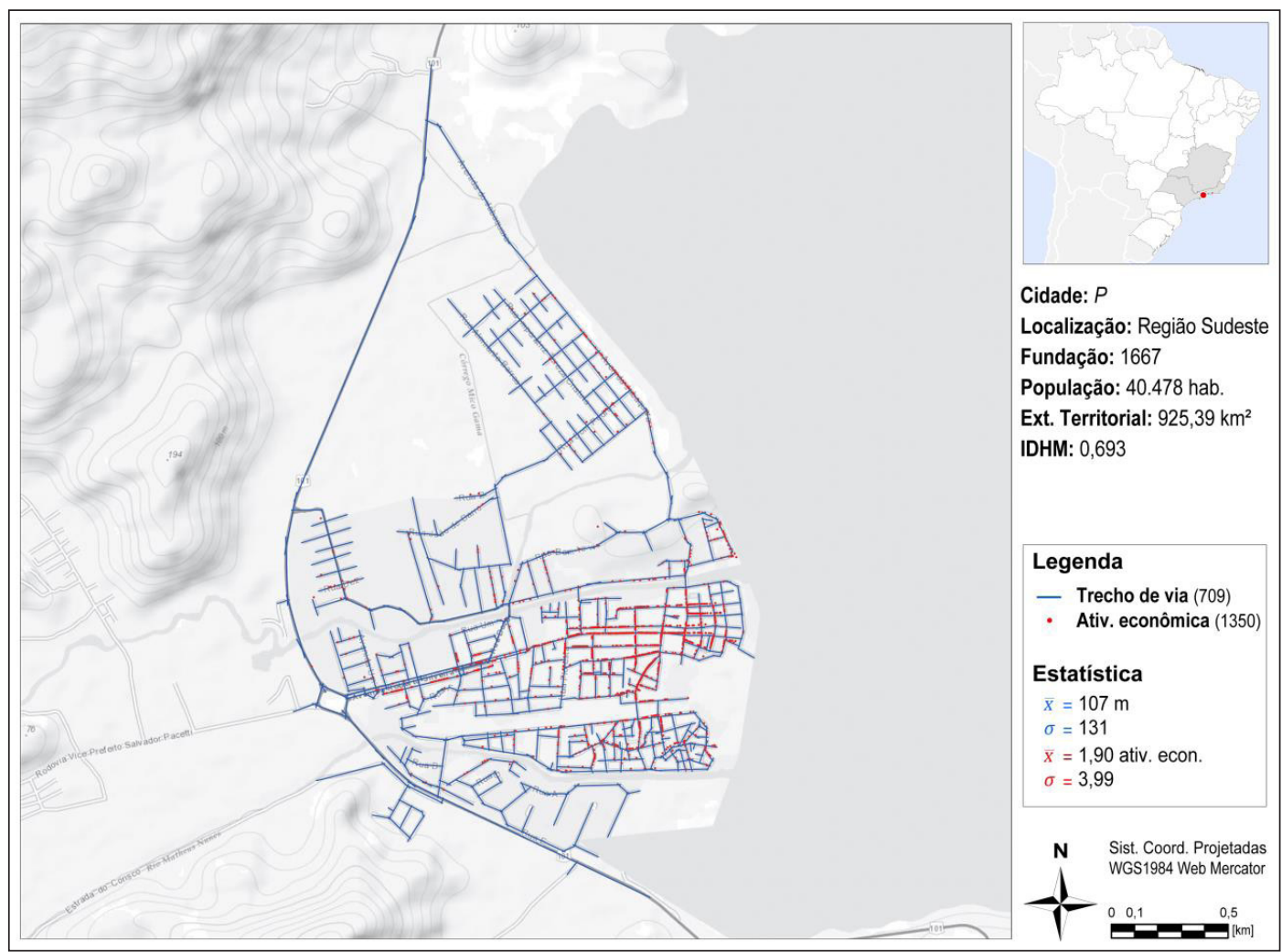

Figura 9 - Cidade P

Fonte: adaptado de Lima (2015). 


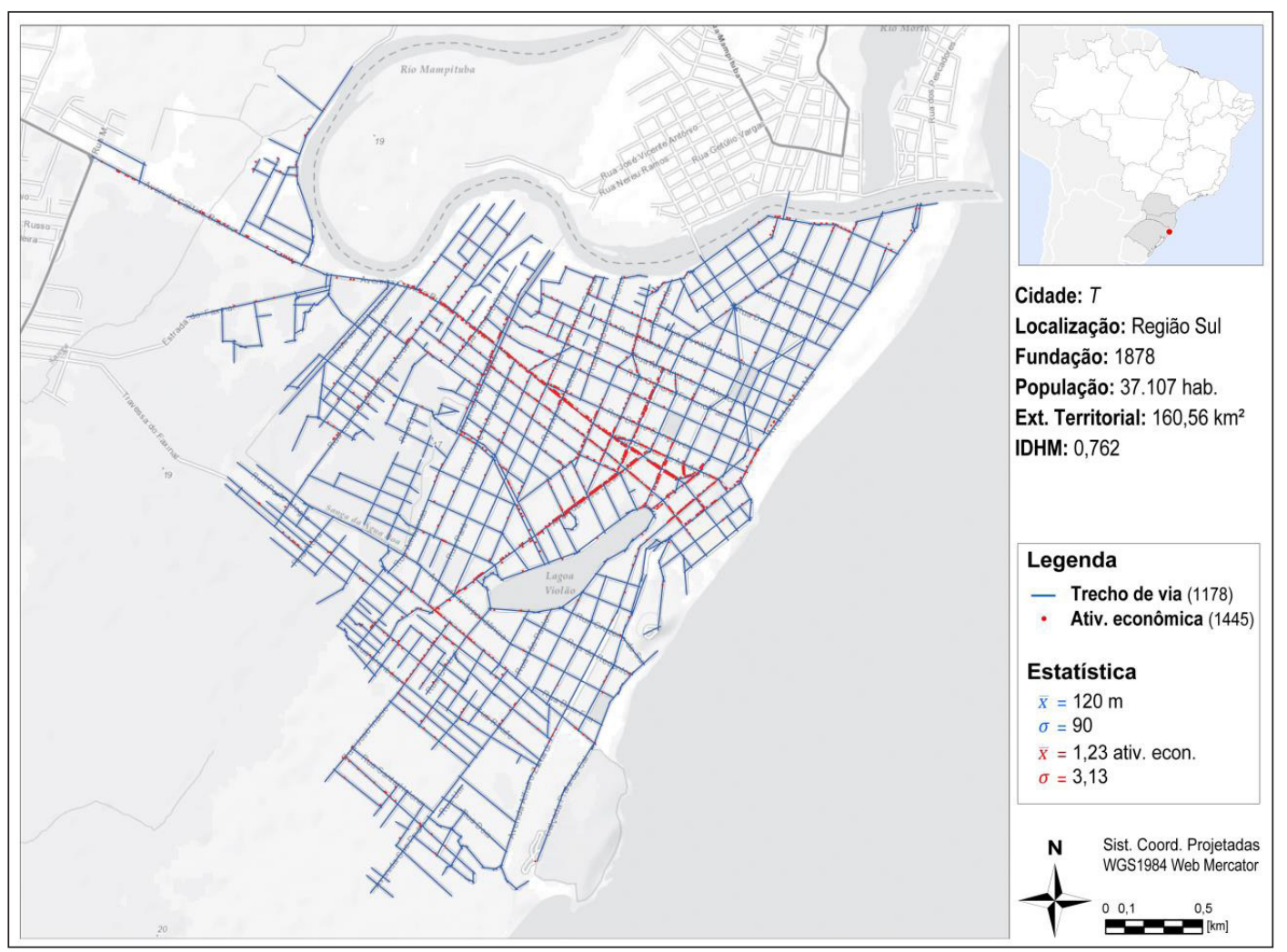

Figura 10 - Cidade T

Fonte: adaptado de Lima (2015).

\section{Experimentos e resultados}

Após a aplicação dos modelos configuracionais propostos sobre a rede espacial de trechos de rua da Cidade $\mathrm{L}$, obteve-se um conjunto de valores de correlação de Pearson ( $r$ ) o qual sugere que o modelo de centralidade por excentricidade processado, considerando-se uma distância igual a $800 \mathrm{~m}$, gera a correlação mais significativa para compreender a forma como as atividades econômicas estão distribuídas sobre essa cidade $(r=0,407)$.

Da mesma forma, entre todos os modelos de centralidade testados sobre a rede formada por trechos de rua da Cidade P, verificou-se que a distribuição de atividades econômicas parece seguir a lógica dada pelo modelo de centralidade por excentricidade, quando esse modelo é processado considerando uma distância igual a $800 \mathrm{~m} .0$ modelo gerou um coeficiente de correlação de Pearson $(r)$ igual a 0,529.

Quando os experimentos foram realizados com os modelos configuracionais aplicados sobre a rede espacial definida por trechos de rua da Cidade T, obteve-se um cenário no qual as atividades econômicas estão distribuídas sobre a malha urbana, conforme aponta o modelo de centralidade por intermediação processado, considerando-se uma distância igual a $1.000 \mathrm{~m}$. Para esse processamento, obteve-se um coeficiente de correlação de Pearson $(r$ ) igual a 0,402.

Na Figura 11, são apresentados os resultados obtidos na aplicação do modelo de centralidade por excentricidade sobre a Cidade $\mathrm{P}$, variando-se os valores de distância imputados no processamento do modelo. Na Figura 11a, apresenta-se a comparação entre a distribuição de atividades econômicas, normalizada pela extensão de cada trecho de rua. 0 mapa da Figura 11b mostra a centralidade por excentricidade local com raio igual a $200 \mathrm{~m}(r=0,262)$. Na Figura 11c, utilizou-se raio igual a $800 \mathrm{~m}$ (maior valor de correlação de Pearson verificado, $r=0,529$ ), enquanto na Figura 11d, raio igual a $3.200 \mathrm{~m}(r=0,35)$.

0 gráfico da Figura 12 demonstra como se dá a dispersão dos valores de centralidade por excentricidade local com raio igual a $800 \mathrm{~m}$ e a relação entre a quantidade de atividades econômicas por extensão dos trechos de rua. Os valores obtidos sugerem que existe uma tendência de quanto maior for a relação 


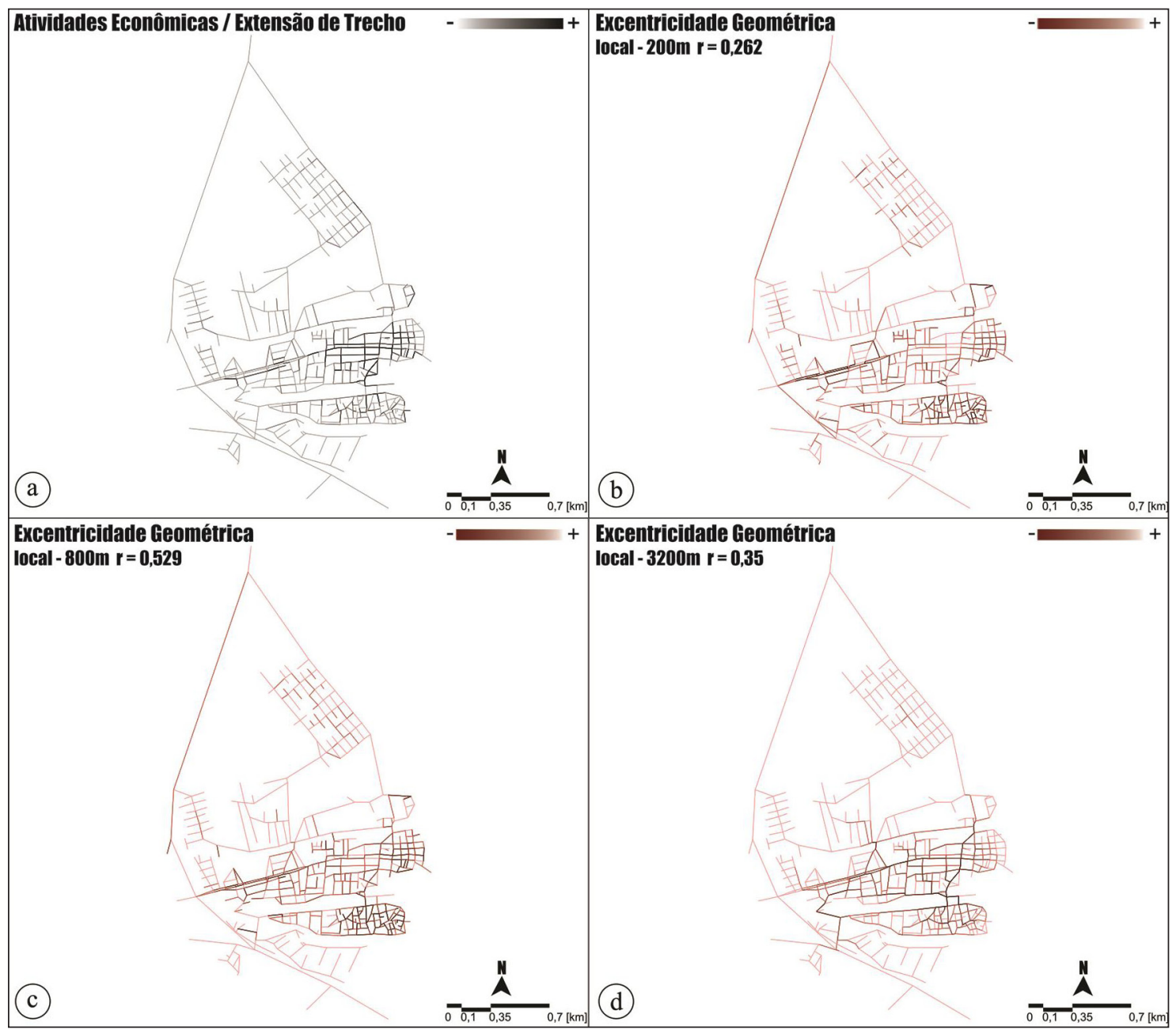

Figura 11 - Resultados do modelo de centralidade por excentricidade na cidade P Fonte: Elaborado pelos autores (2016).

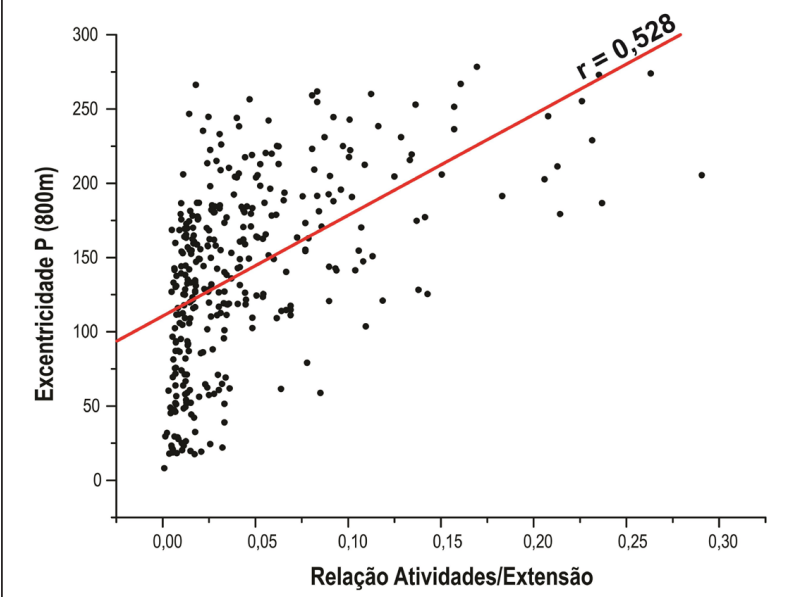

Figura 12 - Dispersão de valores do modelo de centralidade por excentricidade local em P com raio igual a $800 \mathrm{~m}$ e a relação quantidade de atividades econômicas por extensão de trecho de rua $(=0,529)$

Fonte: Elaborado pelos autores (2016). do número de atividades pela extensão dos trechos de rua, maior são os valores de centralidade dos trechos. A quantidade de trechos com altos valores de centralidade e de atividades econômicas por extensão (simultaneamente) também é menor, indicando uma forte hierarquização de pontos que concentram facilidades urbanas.

Os resultados de correlação de Pearson $(r)$ verificados para os experimentos realizados com os modelos de centralidade por alcance, excentricidade, intermediação e proximidade, processados sobre as redes espaciais definidas por trechos de ruas das três cidades analisadas, foram sintetizados na Tabela $1 \mathrm{e}$ representados nos gráficos da Figura 13. Na Tabela 1, estão destacados (em negrito) os maiores valores de correlação obtidos a fim de ilustrar que os modelos configuracionais urbanos que conseguem capturar diferentes propriedades do espaço são capazes, por 
vezes, de chegar a resultados similares, quando se varia apenas a distância considerada no momento do processamento do modelo.
Os resultados demonstram que as correlações mais fortes foram oriundas da Cidade P, isto é, a configuração espacial para essa cidade refletiu de forma mais clara

Tabela 1 - Coeficientes de correlação de Pearson ( $r$ ) obtidos nos experimentos realizados nas cidades L, P e T. Em destaque, as maiores correlações encontradas em cada cidade

\begin{tabular}{|c|c|c|c|c|c|c|c|c|c|c|c|c|}
\hline \multirow{2}{*}{ Raios } & \multicolumn{3}{|c|}{ Alcance } & \multicolumn{3}{|c|}{ Excentricidade } & \multicolumn{3}{|c|}{ Infermediação } & \multicolumn{3}{|c|}{ Proximidade } \\
\hline & L & $\mathbf{P}$ & $\mathbf{T}$ & L & $\mathbf{P}$ & T & L & $\mathbf{P}$ & $T$ & L & $\mathbf{P}$ & T \\
\hline 200 & 0,336 & 0,240 & 0,291 & 0,357 & 0,262 & 0,314 & 0,327 & 0,195 & 0,217 & $-0,162$ & $-0,17$ & $-0,202$ \\
\hline 500 & 0,342 & 0,455 & 0,356 & 0,367 & 0,472 & 0,383 & 0,351 & 0,409 & 0,354 & $-0,093$ & $-0,243$ & $-0,108$ \\
\hline 800 & 0,389 & 0,501 & 0,339 & 0,407 & 0,529 & 0,368 & 0,369 & 0,483 & 0,390 & $-0,054$ & $-0,253$ & $-0,076$ \\
\hline 1100 & 0,389 & 0,478 & 0,348 & 0,405 & 0,507 & 0,380 & 0,391 & 0,485 & 0,402 & $-0,032$ & $-0,220$ & $-0,125$ \\
\hline 1400 & 0,361 & 0,381 & 0,352 & 0,380 & 0,426 & 0,392 & 0,386 & 0,445 & 0,401 & $-0,059$ & $-0,215$ & $-0,144$ \\
\hline 1700 & 0,337 & 0,291 & 0,345 & 0,36 & 0,363 & 0,391 & 0,366 & 0,395 & 0,401 & $-0,043$ & $-0,146$ & $-0,152$ \\
\hline 2000 & 0,328 & 0,251 & 0,344 & 0,355 & 0,336 & 0,392 & 0,348 & 0,354 & 0,396 & $-0,035$ & $-0,079$ & $-0,168$ \\
\hline 2300 & 0,330 & 0,262 & 0,312 & 0,361 & 0,352 & 0,364 & 0,34 & 0,327 & 0,389 & $-0,029$ & $-0,021$ & $-0,164$ \\
\hline 2600 & 0,328 & 0,273 & 0,274 & 0,362 & 0,368 & 0,338 & 0,337 & 0,312 & 0,384 & $-0,034$ & 0,089 & $-0,111$ \\
\hline 2900 & 0,321 & 0,249 & 0,242 & 0,358 & 0,365 & 0,32 & 0,338 & 0,300 & 0,379 & $-0,028$ & 0,330 & 0,033 \\
\hline 3200 & 0,306 & 0,214 & 0,205 & 0,348 & 0,350 & 0,305 & 0,338 & 0,294 & 0,373 & $-0,028$ & 0,417 & 0,298 \\
\hline 3500 & 0,291 & 0,166 & 0,169 & 0,338 & 0,333 & 0,304 & 0,338 & 0,289 & 0,368 & $-0,024$ & 0,439 & 0,400 \\
\hline 3800 & 0,273 & 0,141 & 0,139 & 0,326 & 0,318 & 0,316 & 0,338 & 0,286 & 0,364 & $-0,023$ & 0,437 & 0,394 \\
\hline 4100 & 0,259 & 0,136 & 0,112 & 0,319 & 0,31 & 0,317 & 0,337 & 0,284 & 0,361 & $-0,021$ & 0,434 & 0,382 \\
\hline 4400 & 0,238 & 0,094 & 0,088 & 0,308 & 0,303 & 0,308 & 0,336 & 0,284 & 0,360 & $-0,015$ & 0,435 & 0,376 \\
\hline 4700 & 0,210 & 0,062 & 0,067 & 0,294 & 0,300 & 0,303 & 0,334 & 0,283 & 0,359 & 0,018 & 0,435 & 0,373 \\
\hline 5000 & 0,18 & 0,049 & 0,05 & 0,284 & 0,298 & 0,300 & 0,331 & 0,283 & 0,358 & 0,085 & 0,434 & 0,372 \\
\hline 5300 & 0,157 & 0,049 & 0,043 & 0,281 & 0,298 & 0,299 & 0,329 & 0,283 & 0,358 & 0,188 & 0,434 & 0,371 \\
\hline 5600 & 0,144 & $\cdot$ & 0,037 & 0,29 & 0,298 & 0,298 & 0,327 & 0,283 & 0,358 & 0,294 & 0,434 & 0,371 \\
\hline 5900 & 0,135 & . & - & 0,304 & $\cdot$ & 0,297 & 0,325 & - & 0,358 & 0,334 & - & 0,371 \\
\hline 6200 & 0,119 & - & . & 0,316 & - & - & 0,324 & - & $\cdot$ & 0,339 & - & $\cdot$ \\
\hline 6500 & 0,088 & $\cdot$ & . & 0,32 & . & . & 0,322 & - & - & 0,340 & . & . \\
\hline 6800 & 0,055 & - & - & 0,322 & - & - & 0,321 & - & - & 0,340 & - & . \\
\hline 7100 & 0,037 & - & - & 0,325 & $\cdot$ & - & 0,320 & - & . & 0,339 & - & - \\
\hline 7400 & 0,033 & $\cdot$ & - & 0,33 & - & $\cdot$ & 0,320 & - & $\cdot$ & 0,339 & $\cdot$ & - \\
\hline 7700 & 0,032 & . & . & 0,334 & . & . & 0,320 & . & . & 0,338 & . & . \\
\hline 8000 & 0,028 & - & . & 0,336 & . & . & 0,320 & . & . & 0,338 & . & . \\
\hline 8300 & 0,029 & - & - & 0,338 & $\cdot$ & $\cdot$ & 0,320 & - & $\cdot$ & 0,338 & - & - \\
\hline 8600 & 0,027 & . & - & 0,338 & - & - & 0,320 & - & - & 0,338 & - & - \\
\hline 8900 & 0,024 & . & . & 0,338 & . & . & 0,320 & . &. & 0,338 & . & . \\
\hline 9200 & 0,020 & - & - & 0,338 & $\cdot$ & - & 0,320 & - & - & 0,337 & - & . \\
\hline 9500 & 0,020 & . & . & 0,338 & . & . & 0,320 & . & . & 0,337 & . & . \\
\hline Global & - & - & - & 0,338 & - & - & 0,320 & - & - & 0,337 & - & - \\
\hline
\end{tabular}

Fonte: Elaborado pelos autores (2016). 


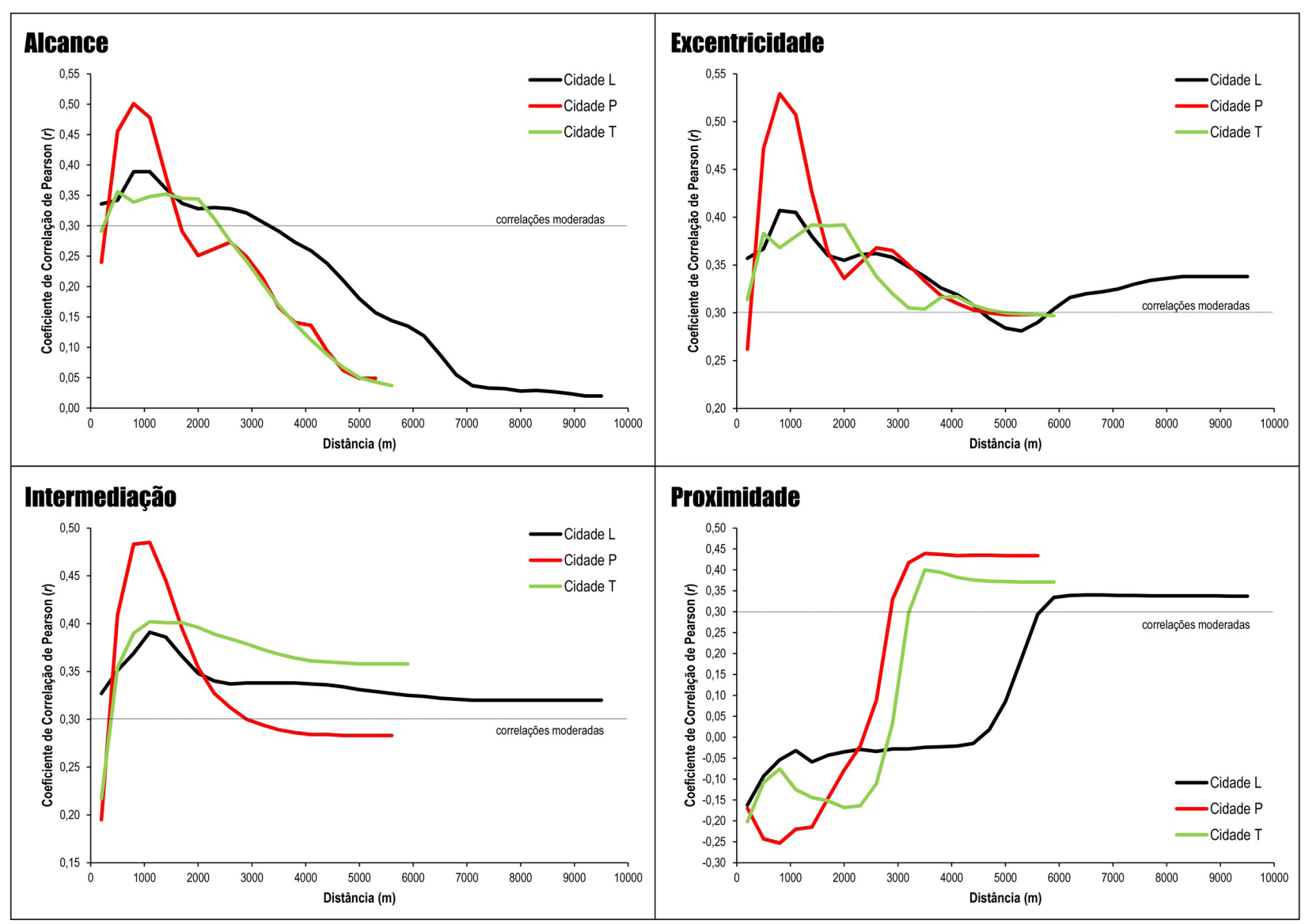

Figura 13 - Variação dos valores da correlação de Pearson obtidos na aplicação dos modelos de centralidade por alcance, excentricidade, intermediação e proximidade, conforme valores de distância (raios) para os experimentos com as três cidades Fonte: Elaborado pelos autores (2016).

a maneira como se dava a distribuição de atividades econômicas. No entanto, as Cidades T e L apresentaram distribuição de atividades econômicas menos suscetíveis à configuração do espaço como ocorre em P. Porém, em todos os casos, foi possível observar picos capazes de descrever, com algum rigor, a maneira como ocorre a distribuição de atividades econômicas nessas cidades e que podem ser verificados nos valores de correlação de Pearson ( $r$ ) obtidos após aplicação de diversos modelos de centralidade com diferentes valores de distância. Destacam-se os modelos de centralidade por alcance e por excentricidade, que atingiram os valores de correlação mais altos observados nos experimentos quando os modelos foram processados com raios iguais a $800 \mathrm{~m}$ (ambos para a Cidade $\mathrm{P}$, com $r=0,501$ e $r=0,529$, para alcance e excentricidade, respectivamente).

Quando da aplicação do modelo de excentricidade por alcance com raio igual a $800 \mathrm{~m}$, teve-se o valor de correlação de Pearson mais significativo desse experimento $(r=0,529)$. Porém, percebe-se uma grande quantidade de valores de correlações obtidos para outros raios de processamento variando pouco em relação a esse valor $(r=0,529)$. Em outras palavras, parece que existem faixas de distância ajustáveis capazes de gerar valores correlacionais mais significativos para os experimentos, de forma tal que, independentemente do modelo, parece ser mais importante otimizar essa distância do que investigar, propriamente dito, qual é o modelo que é mais suscetível a dirigir a distribuição espacial de atividades econômicas urbanas.

\section{Considerações finais}

Esta pesquisa evidencia que, ao se alterar os raios de processamento dos modelos, é possível se obter resultados similares para diferentes rotinas matemáticas. 
Tomando-se como exemplo a Cidade $\mathrm{P}$, a melhor correlação entre centralidades e distribuição de atividades econômicas foi $r=0,529$, aplicando-se o modelo de centralidade por excentricidade com raio igual a $800 \mathrm{~m}$. No entanto, correlações muito próximas dessa foram observadas quando se aplicaram os modelos de centralidade por alcance com raio igual a $800 \mathrm{~m}(r=0,501)$, centralidade por intermediação com raio igual a $1.100 \mathrm{~m}(r=0,485)$ e centralidade por proximidade com raio igual a $3.500 \mathrm{~m}(r=0,439)$. Isso sugere que, para essa cidade, as atividades econômicas pareceram respeitar uma lógica espacial que foi dada, simultaneamente, por aqueles lugares que: (1) apresentavam menor excentricidade dentro de um raio de $800 \mathrm{~m}$; (2) possuíam maior alcance dentro de um raio de $800 \mathrm{~m}$; (3) mais intermediavam deslocamentos dentro de um raio de $1.100 \mathrm{~m}$; finalmente, (4) estavam em média mais próximos dos outros, considerando-se uma distância de $3.500 \mathrm{~m}$.

Já para a Cidade L, a hierarquia dos espaços que mais concentraram atividades econômicas foram os que, simultaneamente: (1) apresentaram os maiores valores de centralidade por excentricidade dentro de uma distância de $800 \mathrm{~m}(r=0,407)$; (2) possuíam os maiores valores de alcance dentro de um raio de $1.100 \mathrm{~m}(r=0,389)$; (3) tinham a maior probabilidade de intermediar deslocamentos dentro de uma distância de 1.100 m ( $r=0,391)$; (4) que estavam, em média, mais próximos dos outros espaços da cidade, em torno de $6.200 \mathrm{~m}(r=0,339)$.

Finalmente, para a Cidade T, há indícios de que a distribuição de atividades econômicas obedeceu a uma regra que foi dada, ao mesmo tempo, pela aplicação do: (1) modelo de centralidade por intermediação dentro de um limite de distância de $1.100 \mathrm{~m}(r=0,402)$; (2) pelo modelo de centralidade por proximidade processado considerando-se um raio de $3.500 \mathrm{~m}(r=0,400)$; pelo modelo de centralidade por excentricidade processado com raios iguais a 1.400 e $2.000 \mathrm{~m}(r=0,392)$; (4) pelo modelo de centralidade por alcance processado com raio igual a $500 \mathrm{~m}(r=0,356)$.

Portanto, parece claro que a maneira como se dá o fenômeno da distribuição de atividades econômicas em cada uma dessas cidades está condicionada por diferentes propriedades espaciais, evidenciadas por distintos índices de centralidade em redes espaciais urbanas, que são associados a diferentes valores de distância ajustáveis no momento inicial do processamento dos modelos. Em outras palavras, mais do que um modelo específico, faz-se mais importante conhecer uma distância que otimiza cada uma dessas propriedades espaciais e que reflete a forma como as atividades econômicas tendem a se distribuir espacialmente sobre a cidade.

É importante frisar que a pesquisa limitou-se a explorar apenas as correlações entre variáveis que estariam linearmente associadas. Contudo, fenômenos urbanos são complexos e possuem relações lineares e não lineares. Acredita-se que, por essa razão, não foram obtidos coeficientes de correlação lineares superiores a 0,6 .

A correlação entre o fenômeno da distribuição de atividades econômicas urbanas e as centralidades propostas pode também ser analisada por meio de estatísticas voltadas à identificação de correlações entre variáveis que não são linearmente correlacionadas. Assim, poderiam ter sido realizados testes como o coeficiente de correlação Spearman ou o Tau de Kendall.

Ferramentas de mineração de dados também são recursos potenciais para aumentar o poder de análise de dados em estudos urbanos (Korting et al., 2013), uma vez que tais técnicas são capazes de rapidamente selecionar os atributos mais representativos de cada classe de objetos e gerar regras de classificação simples. Além disso, a mineração de dados pode lidar com grandes bases de dados complexos e ser adequada para enfrentar dinâmicas multidimensionais, como o crescimento urbano (e.g., Pinzón \& Souza, 2016).

Essas colocações evidenciam que há muito a ser explorado nesse tema, aplicando-se diferentes metodologias para análise de fenômenos urbanos e de propriedades espaciais das redes em que se inserem, o que gera uma ampla gama de possibilidades a experimentar em estudos posteriores (Lima, 2015, p. 139).

\section{Agradecimentos}

Os autores agradecem à CAPES - Coordenação de Aperfeiçoamento de Pessoal de Nível Superior pelo apoio financeiro à execução deste trabalho sob forma de bolsa de doutorado.

\section{Referências}

Barra, T. (1979). Integrating micro-economic models with spatial interaction theory. In P. Steadman (Ed.), Transactions of the Martin Centre for Architectural and Urban Studies (p. 231-273). Cambridge: University of Cambridge. 
Blanchard, P., \& Volchenkov, D. (2009). Mathematical analysis of urban spatial networks. Heidelberg: SpringerVerlag Berlin.

Crucitti, P., Latora, V., \& Porta, S. (2006). Centrality measures in urban networks. Physical Review E: Statistical, Nonlinear, and Soft Matter Physics, 73(3), 036125. PMid:16605616. http://dx.doi.org/10.1103/PhysRevE.73.036125.

Echenique, M. (1975). Modelos Matemáticos de la estructura espacial urbana, aplicaciones en América Latina. Buenos Aires: Ediciones SIAP/Ediciones Nueva Visión.

Freeman, L. C. (1977). A set of measures of centrality based on betweenness. Sociometry, 40(1), 35-41. http:// dx.doi.org/10.2307/3033543.

Haggett, P., \& Chorley, R. (1969). Network analysis in geography (2a ed., Vol. 1, Explorations in Spatial Structure). Londres: Edward Arnold.

Hansen, W. G. (1959). How accessibility shapes land use. Journal of the American Planning Association, 25(2), 73-76.

Hillier, B., Penn, A., Hanson, J., Grajewski, T., \& Xu, J. (1993). Natural Movement - or, configuration and attraction in urban pedestrian movement. Environment \& Planning B, 20(1), 29-66. http://dx.doi.org/10.1068/b200029.

Ingram, D. R. (1971). The concept of accessibility: a search for an operational form. Regional Studies, 5(2), 101-107. http://dx.doi.org/10.1080/09595237100185131.

Instituto Brasileiro de Geografia e Estatística - IBGE. (2013). PlataformaCidades@. Rio de Janeiro: IBGE. Recuperado em 2 de fevereiro de 2014, de http://cidades.ibge.gov.br/ xtras/home.php?lang=.

Korting, T., Fonseca, L. M. G., \& Câmara, G. (2013). GeoDMA Geographic Data Mining Analyst a framework for GIScience. Computers \& Geosciences, 57, 133-145. http://dx.doi. org/10.1016/j.cageo.2013.02.007.

Krafta, R. (1994). Modelling intraurban configurational development. Environment \& Planning B, 21(1), 67-82. http://dx.doi.org/10.1068/b210067.

Krafta, R. (2014). Notas de aula de morfologia urbana. Porto Alegre: UFRGS.

Kruger, M. J. T. (1979). An approach to build-form connectivity at urban scale: variations of connectivity and adjacency measures amongst zones and other related topics. Environment \& Planning B, 6(3), 305-320. http:// dx.doi.org/10.1068/b060305.

Lima, L. (2015). Centralidades em redes espaciais urbanas e localização de atividades econômicas (Dissertação de mestrado). Faculdade de Arquitetura, Programa de
Pós-graduação em Planejamento Urbano e Regional, Universidade Federal do Rio Grande do Sul, Porto Alegre. Moraes, V., No., \& Jelvez, A. Q. (2009). O Espaço urbano como dimensão ativa na incidência do crime. Recuperado em 30 de janeiro de 2014, de http://urbanismo.arq.br/ metropolis/2009/05/05/.

Nystuen, J. (1968). Identification of some fundamental spatial concepts. In J. Berry \& D. Marble (Eds.), Spatial analysis: a reader in statistical geographic (p. 35-41). Londres: Prentice-Hall.

Pearson, K. F. R. S. (1900). X. On the criterion that a given system of deviations from the probable in the case of a correlated system of variables is such that it can be reasonably supposed to have arisen from random sampling. Philosophical Magazine Series 5, 50(302), 157-175. http:// dx.doi.org/10.1080/14786440009463897.

Pinzón, D. F. D. B., \& Souza, F. T. (2016). A data based model as a metropolitan management tool: The Bogotá-Sabana region case study in Colombia. Land Use Policy, 54, 253263. http://dx.doi.org/10.1016/j.landusepol.2016.02.019.

Porta, S., Latora, V., Wang, F., Rueda, S., Strano, E., Scellato, S., Cardillo, A., Belli, E., Cárdenas, F., Cormenzana, B., \& Latora, L. (2011). Street centrality and the location of economic activities in Barcelona. Urban Studies, 49(7), 1-18.

Sevtsuk, A. (2010). Path and place: a study of urban geometry and retail activity in Cambridge and Somerville, MA (Ph.D. thesis). Massachussets Institute of Technology, Cambridge.

Sevtsuk, A., \& Mekonnen, M. (2012). Urban network analysis. A new toolbox for ArcGIS. International Journal of Geomatics and Spatial Analysis, 22(2), 287-305.

Strogatz, S. H. (2001). Exploring complex networks. Nature, 410(6825), 268-276. PMid:11258382. http://dx.doi. org/10.1038/35065725.

Vragović, I., Louis, E., \& Díaz-Guilera, A. (2005). Efficiency of information transfer in regular and complex networks. Physical Review E: Statistical, Nonlinear, and Soft Matter Physics, 71(036122), 1-10.

Wasserman, S., \& Faust, K. (1994). Social network analysis: methods and applications. Cambridge: Cambridge University Press.

Watts, D. J. (2004). Six degrees - the science of a connected age. New York: W. W. Northon \& Company.

Recebido: Fev. 26, 2016

Aprovado: Jul. 27, 2016 